\title{
DISSONANCE OF SELECTED NEUROSCIENCE TECHNIQUES AT DETECTION OF EMOTIONS IN ADVERTISING SPOTS
}

\author{
Katarína Neomániová ${ }^{1}, J^{2}$ akub Berčík ${ }^{1}$, Elena Horská ${ }^{1}$ \\ 'Department of Marketing and Trade, Faculty of Economics and Management, Slovak University of Agriculture, \\ Tr. A. Hlinku 2, 94976 Nitra, Slovakia
}

\begin{abstract}
NEOMÁNIOVÁ KATARÍNA, BERČÍK JAKUB, HORSKÁ ELENA. 2018. Dissonance of Selected Neuroscience Techniques at Detection of Emotions in Advertising Spots. Acta Universitatis Agriculturae et Silviculturae Mendelianae Brunensis, 66(4): 969-977.

In addition to advanced brain imaging techniques and growing interest in the study of consumer reactions with influence of marketing stimuli a new interdisciplinary study has developed on a borderland of neuroscience, economic and psychological studies - neuromarketing. Despite a certain form of insecurity whether the brain imaging technologies provide useful information for control of marketing, more and more marketers identify with their application in conventional market research. The main aim of this contribution is to clarify the influence of a selected advertising spot on the final emotional state of consumers by researching a brain activity of respondents and activity of somatic nervous system, specifically the face expressions. Cortical brain activity was detected by 16channel wireless electroencephalograph by Epoc and changes of mimic muscles were monitored by a biometric device the Facereader by Noldus. The subject of the research is the dissonance of the selected neuroscience techniques with influence of chosen advertising emotional appeals like fear, disgust and sadness. In the end of our contribution, the way of using the neuroscience technology and psychology for detection of consumer emotional involvement of consumers is explained.
\end{abstract}

Keywords: brain imaging technologies, advertising, emotions, Software Facereader 6, Noldus, Emotiv Epoc EEG

\section{INTRODUCTION}

New discoveries in the neuroscience represent the revolution of the $21^{\text {st }}$ century and marketing is not an exception. Marketers are more and more skeptical of using traditional research methods because they represent a limitation of an effective measurement of internal reactions to external stimuli. Final state that people experience cannot be measured adequately by self-reported verbal indicators, because of their complexity and non-propositional structure. (Davidson, 2004). It is concluded from many researches that threshold of our conscious perception starts to be fully active $300 \mathrm{~ms}$ after the stimuli what means that most of activities lasting less cannot be adequately verbally evaluated (Libet,
2004). The base for the neuromarketing research is a finding that $95 \%$ of human thinking and activities happen in the subconscious (Kozel et al., 2011), what adds to the fact that sophisticated brain imaging and biometric methods which can penetrate into the subconscious consumer processes are being brought to the foreground.

Modern neuroscience tools which help to see into human brains open a way to psychological decision making process - black box of the brain (Dooley, 2012). An insight to subconscious brain processes is a key area of the neuromarketing representing a new type of the marketing research, and it studies motor and sensory, cognitive and affective reactions of consumers to marketing stimuli (Berčík et al., 2014). Scientists thanks to technologies 
like Functional Magnetic Resonance Imaging (fMRI), electroencephalography (EEG), in a more modern form Steady State Topography (SST) and measurements of physiological reactions (frequency of heart and breath and galvanic reactions of skin, face expression) find out how the consumers make unconscious decisions and which part of brain dictates it to them (Roebuck, 2011).

From the point of view of psychology supporting the marketing research and experimental studies with the usage of neurophysiological techniques, the main intention is usually to research cognitive or affective consumer processes in reactions to effecting marketing stimuli. These cognitive or affective processes, individually or together, serve as psychological predecessors to different neuropsychological consequences produced in the human nervous system. Via combination of various neurophysiological methods, it is possible to verify the cross validity of external marketing stimuli effecting the consumer perception (Ohme et al., 2009).

The aim of neuromarketing techniques is an analysis of brain activities and recording of relations between nervous system and behaviour of consumers. These mentioned methods are focused especially on research of consumer behaviour, perception and decision making while they can be divided into (Zurawicki, 2010) methods of measurement of biometric signals and methods of measurement of brain signals.

Biometrics is a universal term which represents measurement of physiological responses of a body - not brain directly - to external stimuli perceived via senses. From the point of view of neuromarketing, one of the most used biometric measurements is the heart and breathing activities, eye movements, blinking, galvanic skin resistance (GSR), mimics and body movements. Some biometric measurements are limited to purposes of neuromarketing research because they are delayed indicators (indirect measurements) of primary brain activity while brain can give an order to body ahead enough of a physiological effect. An ideal case is a finding when the brain gives the order not only when it is being conducted (Pradeep, 2010).

Neurological (neurometric) indicators (on the brain signals basis) are more complex, but at the same time more precise and detailed than biometric quantities (Vecchiato et al., 2013). In case of these measurements, it can happen a situation that effort and expenses related to a usage of techniques necessary for neuroresearch realisation are often higher than an asset of relevant information. On the other hand, it is important to stress that it is mostly a question of correct set of research aims. Technologies which measure the brain activity are often called brain imaging because they include images or pictures presenting the brain activity (Genco et al., 2013). Regardless the fact that in the last ten years many authors researched the justifiability (acceptability) of brain waves measurement technologies (EEG and the more modern form
SST) to understand the processing of advertising stimuli (appeals), number of relevant and respected scientific studies is considerably small. (Wang and Minor, 2008).

In advertising it is possible to use this interdisciplinary approach to identify the key areas (the greatest attention, the emotional response) and also to select the relevant advertising spot from several variants for use in a specific medium. This article has just focused on detecting the emotions caused by advertising spots using various neuromarketing techniques to reveal any dissonance between them.

Emotional reactions evoked by advertisement (social spot about discrimination against women) tried to measure e.g. Mauri et al. (2014). In research were used as techniques of traditional marketing research (questionnaires) as well as some neuroscientific techniques (eye-tracking, face expression analysis and electroencephalography). The research was conducted on a sample of 60 university students. From the survey results Mauri et al. (2014) concluded that integrated approach can provide more accurate information enabling to better understand the evaluation processes of subjects.

How integration of two neuroscience methods (electroencephalography and eye-tracking) can help to better understand emotional reactions of consumers by seeing advertisement show also the research conducted by Ohme, Matukin and Pacula-Lesniak (2011). They tested two DVD covers with and without award information. Eye-tracking measures showed that a more effective version will be the cover without the awards information. According to EEG measurements the both covers were perceived equal. Finally the integrated EEG and eye-tracking approach detected that more effective DVD cover will be with the award information. Therefore Ohme, Matukin and Pacula-Lesniak (2011) believe that the integrated approach provides more useful information for marketing managers.

\section{MATERIALS AND METHODS}

Subject of the research is dissonance of selected neuroscience techniques with influence of chosen advertising emotional appeals like fear, disgust and sadness. On the basis of the advertising test in simulated laboratory conditions with the usage of EEG device and Facereader software, we tried to reveal an emotional state (valence) under conditions of different video and audio appeals. Normally is used a two-dimensional space (valence/arousal) to describe emotions. However, in this research is used only one dimension (valence). a similar approach was applied also in research of Önal-Hartmann, Ocklenburg and Güntürkün (2012).

Primary research comprised of consumer neurological tests, specifically brain and somatic nervous system activity monitoring via face expressions during broadcasting of a specific 
advertising spot, while the experiment attended 16 respondents ( 8 men and 8 women). The sample size is comparable to other measurements in this area. E.g. Nagel (2014) argues that each study is unique in its own way and many researchers in neuromarketing work only with about 20 respondents.

The target segment of respondents was represented by students aged 18-24 because the watched social advertising spot was focused on the issue of irresponsible driving and according to the statistics the most traffic accidents are caused by young drivers within 5 years of obtaining a driving license (Teraz.SK, 2017). Prior to testing, respondents were familiarized with the entire testing process, used instruments and signed a consent to the recording and processing of biometric data for research purposes. The neuromarketing study was conducted in accordance with the internal code of ethics of the Slovak University of Agriculture in Nitra, which is developed in accordance with the ICC/ESOMAR International Code on Market and Social Research and with the NMSBA (Neuromarketing Science and Business Association) Code of Ethics.
For data collection of brain activity we used Emotive EPOC headset which contains 14 data collection electrodes and 2 reference electrodes placed and marked in compliance with the international 10-20 system of electrode placement. Following the international norms of the American Electroencephalographic Society (1994) and according to Nuwer et al. (1998) in available places were: AF3, F7, F3, FC5, T7, P7, O1, O2, P8, T8, FC6, F4, F8 and AF4. Fig. 1 depicts 14 positions of electrodes of Emotive EPOC headset.

For data collection of somatic nervous system via face expressions, Microsoft LifeCam Studio web camera with HD and 1080p resolution was used (Fig. 2). The advertising stimulus was played to researched subjects on Philips LCD television and SHP1900 audio headphones.

There are different approaches how to measure and analyze facial expressions e.g. Facial Action Coding System (Ekman and Friesen, 1978) or facial electromyography which was used e.g. in experiment conducted by $\mathrm{Hu}$ et. al. (1999). In our research changes of mimic muscles were monitored by a biometric device the Facereader by Noldus.

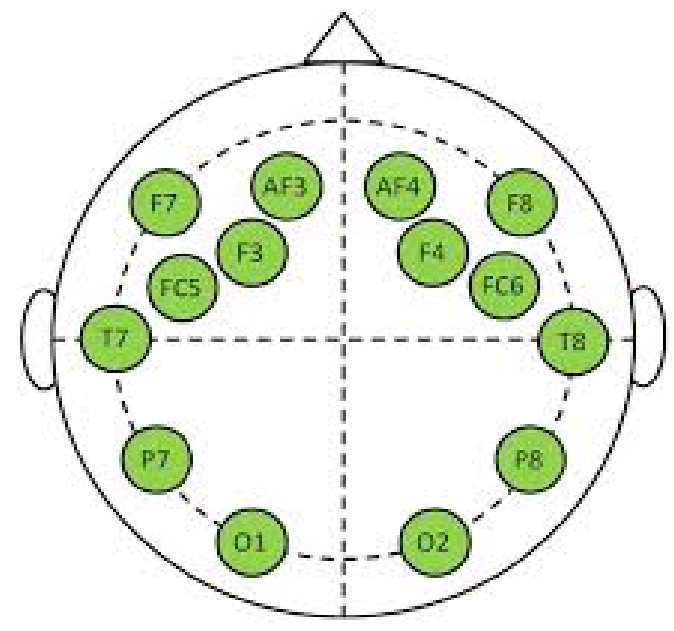

1: 10-20system Emotiv EPOC

Source: http://www.people.vcu.edu/ mmanic/images/ResearchDetail/RoboticsDetail/EmotivHMI/Emotiv_3.png

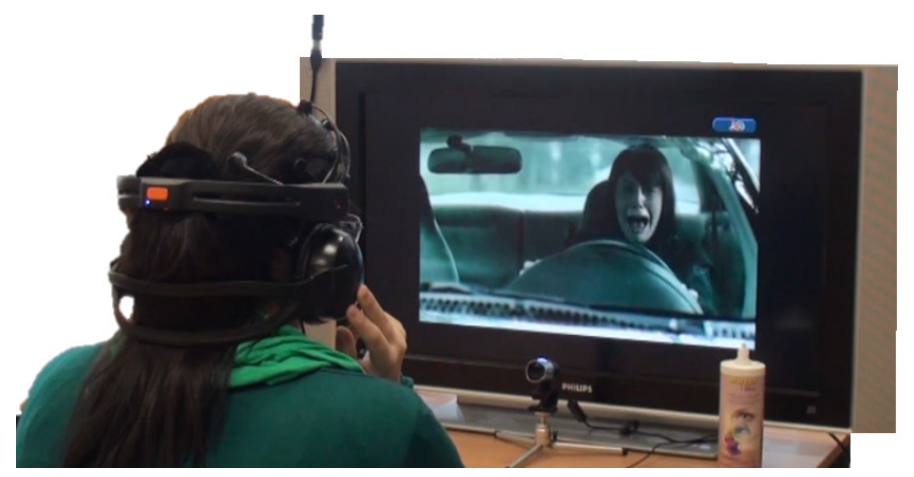

2: Usage of Facereader at researching consumer valence Source: authors' own production 
Automated system Facereader works in three steps: face detection, face modelling and following classification. Initial exact position of a face was found by the Active Template Method function. Another Active Appearance 3D Modelling function provided a synthesis with an artificial face model which describes placement of 491 key points as well as an exact face structure. Results were primary data of face expressions which were classified automatically to six basic expressions: happy, sad, angry, surprised, fear and disgusted. From the measured data we calculated the average values of the individual emotions at respondents measured during video watching and we gained 16 values, i.e. one for each respondent. We calculated the average and standard deviation from these values. Then we researched time series of the valence (positive, negative and neutral feelings) recorded via the face expressions and brain activity of the researched subjects. EEG signals in the alpha $(7-13 \mathrm{~Hz})$ and beta zone $(13-30 \mathrm{~Hz})$ are in the centre of interest while researching the emotional valence and excitement. Presence of EOG factors (eye movements/blinking) is dominant mostly $14 \mathrm{~Hz}$, EKG (heart) artefacts around $1.2 \mathrm{~Hz}$ and EMG (muscle) artefacts over $30 \mathrm{~Hz}$. Non-physiological artefacts caused by electrical lines are normally present $50 \mathrm{~Hz}$ (Ramirez et al., 2012). The advantage is that at extra alpha and beta frequency is significantly reduced a content of side interfering elements (noises) in the EEG signals. That is a reason why it was necessary to apply a filtration inevitable for extraction of alpha and beta frequency zones. By using fast Fourier Frequency Transformation (FFT) is the original signal divided in time to frequencies to remove specific (unnecessary) frequencies before regressive transformation to signal with the frequency of interest (Lin et al., 2008). To be able to determine the valence (emotional) level of negative or positive states of mind we compared levels of activation of two cerebral cortex hemispheres. F3 and F4 electrodes are the most used positions when looking at the alpha activity because it is typical for prefrontal lobe which plays a key part in regulation of the emotions and conscious experience. Revealing the valence value will be conducted by the means of calculation and comparison of alpha and beta value in F3 and F4 canals (Petrantonakis, 2011). Formula for calculating of valence (emotions) value is:

$V=\frac{a F 4}{b F 4}-\frac{a F 3}{b F 3}$

where:

$\mathrm{aF} 4$ = alpha activity in right prefrontal electrode F4 bF4 = beta activity in right prefrontal electrode F4 aF3 = alpha activity in left prefrontal electrode F3 bF3 = beta activity in left prefrontal electrode F3 Final valence values detected by Facereader software are automatically processed on the basis of summary of six basic emotions classified to positive and negative. We measured emotions in ten-seconds-long intervals. For comparison we created to the individual time sequences of frequencies of prevailing emotions (valence) detected by both types of devices. We used descriptive statistics methods - arithmetic mean, standard deviation to evaluate. We used these methods to calculate the overall impression of the video, i.e. intensity of felt emotions of a whole sample. We used descriptive statistics methods - arithmetic mean to investigate time series. Methodology of research and evaluation of the influence of the advertising appeal on consumer emotions was executed in the presence of erudite neurologist with a certificate for EEG.

\section{RESULTS}

To compare two considerably often used techniques of neuromarketing research, we have chosen a social advertising spot with an educative character as a stimulus. The advertising used represents prevention from fast, unforesighted driving and it was a part of media campaigns in many states of Canada in 2010. This advertising spot contains a combination of a strong appeal, for instance fear, surprise and sadness what creates an expectation to record a specific valence state of respondents during video watching as well as following correlation.

Video is divided into time sequences of 10 seconds (Tab. I) and we marked them with an interval class mark (middle of class interval):

- Scene I.-5 (start-10 $0^{\text {th }}$ second): Man is driving in a hurry to pick up his children from school. It can make a negative or neutral impression on respondent.

- Scene II-15 (10 ${ }^{\text {th }}-20^{\text {th }}$ second): Young woman surrounded by her friends recollects after a while that she forgot to pick up her sibling from school. It can make a negative or neutral impression on respondent.

- Scene III.-25 (20 $20^{\text {th }}-30$ second): Young woman is getting in a car and driving fast, she wants to rectify her mistake. It can make a negative impression on respondent.

- Scene IV.-35 $\left(30^{\text {th }}-40^{\text {th }}\right.$ second): Children are leaving school. Man stops car in front of the school, his children are running to him.

- Scene V. $-45\left(40^{\text {th }}-50^{\text {th }}\right.$ second): There is a crash of a young girl. It can make a negative impression on respondent.

- Scene VI. $-55\left(50^{\text {th }}-60^{\text {th }}\right.$ second): Young driver is shocked. It can make a negative impression on respondent.

- Scene VII. 65 ( $60^{\text {th }}-70^{\text {th }}$ second): Help is coming to the place of accident.

- Scene VII. $75\left(70^{\text {th }}-80^{\text {th }}\right.$ second): Doctors try to save young girl.

- Scene IX. 85 (80 $80^{\text {th }}-90^{\text {th }}$ second): Girl is transported to hospital. 
- Scene X. 95 ( $90^{\text {th }}-100^{\text {th }}$ second): Desperate father is supporting his son whose sister was crashed by car.

- Scene XI 105 (100 th $-110^{\text {th }}$ second): Mother is supporting her daughter who hit the young girl.

- Scene XII 115 (110 th $-120^{\text {th }}$ second): Hope or hopeless state after telling news to the father about girl.

From data detected via Facereader device we calculated average values of the individual emotions at respondent measured during whole video watching. Consequently we got 16 values, i.e. one for each respondent from which we calculated the average and the standard deviation, as shown Tab. II.

Highest value of the average values of emotions was detected at the neutral type what can be caused by the fact that the activity of somatic nervous system can be influenced to a certain level (the respondent can control his face expression). Another reason of this can be a certain limitation of the software solution when detecting the face expressions while the software is not directly connected by electrodes to the mimic muscles. On the other hand, the high level of neutrality from the emotions point of view can really conclude from the video stimulus itself which can be for some of the tested subjects considerably known and it results in a significant decrease of emotional expression. On the basis of the calculated average values, it is possible to put in order the prevailing emotions according to a rate of their intensity under the influence of the played video:

1. neutral,

2. sad,

3. surprised,

4. other,

5. angry.

Emotions of happy and disgusted type are not mention because of their zero-level occurrence. This final state can be reasoned by not present appeals which provoke feelings of happiness, disgust in the stimulus or a certain restriction of this method when detecting very small emotional expressions (which are not realised on a face). The face expression which does not correspond with any predefined model (happy, sad, angry, ...) is put into category "other". In some cases it can be caused by poor lighting conditions or by angel of camera rotation which should be 40 degrees. As we see that the standard deviation of non-zero emotions is considerably high (apart from other emotion), it is also relevant to investigate the time series where we researched emotions (valence) only as positive/neutral/negative.

As is concluded from Fig. 3 on the basis of results of the biometric method of emotional state recognition at respondents dominate neutral to

\section{I: Description of individual video sequences}

\begin{tabular}{|c|c|c|c|c|c|}
\hline Time & Picture & Time & Picture & Time & Picture \\
\hline $\begin{array}{l}\text { I. } \\
5\end{array}$ & & $\begin{array}{l}\text { II. } \\
15\end{array}$ & & $\begin{array}{l}\text { III. } \\
25\end{array}$ & \\
\hline IV. & & V. & & VI. & \\
\hline VII. & & VIII. & & IX. & \\
\hline X. & & XI. & & XII. & \\
\hline 95 & & 105 & & 115 & \\
\hline
\end{tabular}

Source: authors' own production

II: Average and standard deviation of basic emotion types

\begin{tabular}{cccccccc}
\hline Measure & Happy & Sad & Angry & Surprised & Disgusted & Neutral & Other \\
\hline Average & 0 & 19.51 & 2.92 & 4.38 & 0 & 69.61 & 3.53 \\
St.deviation & 0 & 24.27 & 11.68 & 13.47 & 0 & 27.08 & 2.51 \\
\hline
\end{tabular}

Source: authors' own production 
negative emotions during watching of the social advertising. That can be caused by the facts mentioned above. Most of the negative emotions recorded by this method were detected in the time interval from $50^{\text {th }}$ to $60^{\text {th }}$ second, most probably by a strong emotional appeal in the used advertising stimulus (car crash of the child participant). a small amount of positive emotions was detected via this non-contact method in the first 10 seconds of the video, in the interval from $20^{\text {th }}$ to $40^{\text {th }}$ seconds and finally in the intervals from $80^{\text {th }}$ to $100^{\text {th }}$ seconds. The positive emotions in the first seconds of the video and in the interval from 20 to 40 seconds can cause routine activities presented in the video. However, the positive emotions in the intervals from $80^{\text {th }}$ to $100^{\text {th }}$ seconds can be connected with the moment of surprise, hope to a sudden shift of action or a certain anomaly which appears as a result of concentration interruption and overall emotional state of the researched subject.

In Fig. 4, it is possible to see that on the basis of results of the brain activity measurements, the negative emotions at researched subjects are dominant. The positive and neutral emotions of the researched subjects are equal which concludes to the fact that measurement of valence via brain imaging technology is more precise than measurement with the biometric method which showed predominance of neutral feelings in the most of the time intervals. In this case, a certain anomaly in the intervals from $50^{\text {th }}$ to $70^{\text {th }}$ second and in the interval from $90^{\text {th }}$ to $100^{\text {th }}$ second appears because they are the time series in which the video appeals (influences) to the negative emotions despite that the positive emotions were recorded there at some researched subjects. This phenomenon can be caused by disturbing influences which arises during measurement of electrical brain activity, or respondents fail to concentrate during the stimulus being played, for instance as a result of tiredness.

Prevailing emotions in individual time sequences detected by scanning face expressions and electrical brain activity are shown in Tab. III.

In Fig. 5, we compare the average values of the valence detected via Facereader software and electroencephalograph (EEG) in the individual time intervals (x-axis). The course of the valence is almost the same at both technologies; more emotions of negative type are present. In the time interval from $80^{\text {th }}$ to $90^{\text {th }}$ second according to Facereader and from $90^{\text {th }}$ to $100^{\text {th }}$ second according to EEG are negative emotions not so strong because in these intervals appeared positive emotions, too.

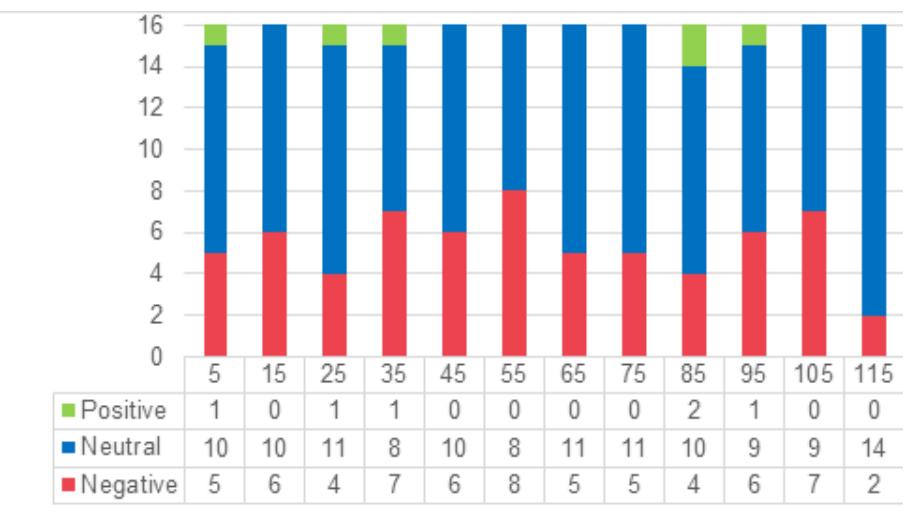

3: Valence of respondents recorded by Facereader device Source: authors' own production

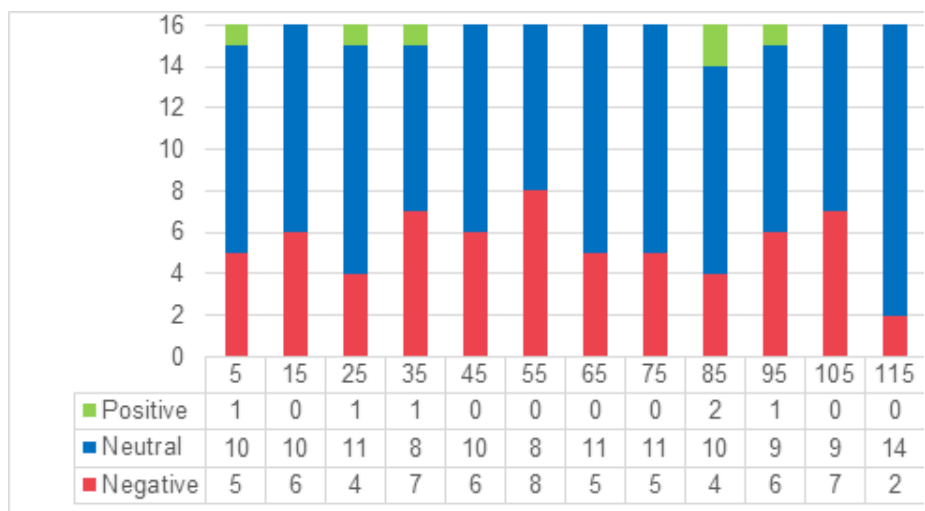

4: Valence of respondents recorded by electroencephalograph Source: authors' own production 
This caused that the average value started to come closer to the neutral emotions and the positive impulse could have been caused by the fact that the respondent expected the final shift of the action that the girl would be cured in the end.

\section{DISCUSSION}

Dissonance of selected neuroscience techniques at detection of emotions has been the subject of several studies. In the study by Soleymani et al. (2015), which was focused on the comparison of facial expression valency with EEG, found that facial recognition of emotions is a more reliable tool for valence determination than EEG because facereading can already capture subtle changes in facial expressions which does not appear in the signals recorded by the EEG. The results of another study (Koelstra and Patras, 2013) also demonstrated that facial expressions had superior performance compared to the EEG signals for emotion detection. At the same time but this study stated that these measurements cannot be generalized to all emotional recognition scenarios which our study confirmed as well. Based on the data we have gained in our research, monitoring of electrical brain activity by electroencephalography appears to be a more reliable valence detection tool. Smaller emotional expressions recorded through facial expressions can be caused by the appeal used (we used sadness/fear and they in the study humor) and, to a great extent, also by laboratory conditions. The lab is typically not a very natural or social environment. This may lower the chance that participants show intense expressions (Noldus Information Technology, 2018). Therefore we plan to repeat a similar study in the future, in which we will try to involve participants much more with self-relevant stimulus material or by creating a social interaction. On the other hand, under the laboratory conditions it is possible to guarantee the same light conditions, which are very important for emotional monitoring based on facial expressions because some studies have noted that visual confounds such as inadvertent shading can lead to pop-out regardless of emotional expressions (Purcell, Stewart and Skov, 1996). To gain exact results we recommend to combine the brain imaging technologies with the biometric methods which monitor the somatic and autonomous nervous system activity. a similar approach was applied also in research of Mauri et al. (2014) or Ohme, Matukin and Pacula-Lesniak (2011). Based on the mentioned above, we plan to conduct future research by using 32-channel electroencephalograph from G-tec for more detailed information on electrical brain activity, which will contribute to more accurate recognition of valency when viewing commercials. At the same time, we plan to use also other emotional appeals (such as humor) to better compare the validity of getting positive and negative valency through the biometric and neuro-imaging method.

III: Prevailing emotions in individual time sequences detected by scanning face expressions and electrical brain activity

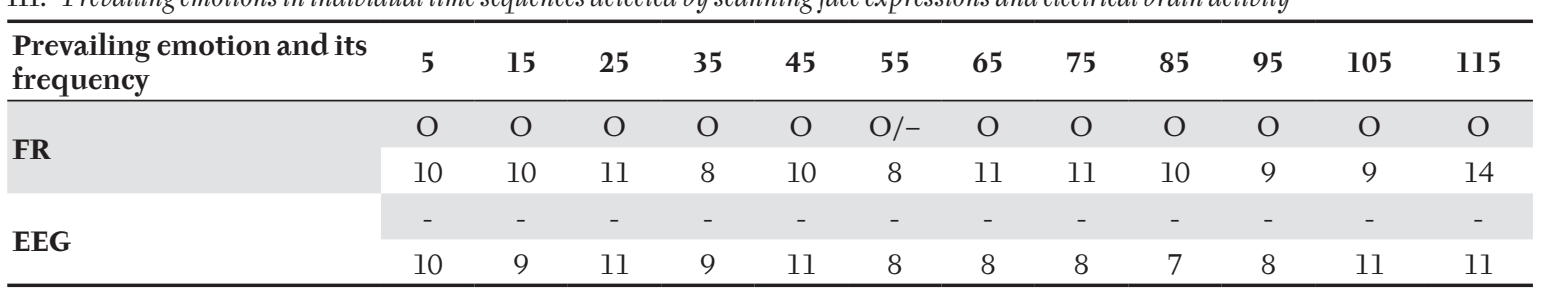

Legend: O neutral, - negative

Source: authors' own production

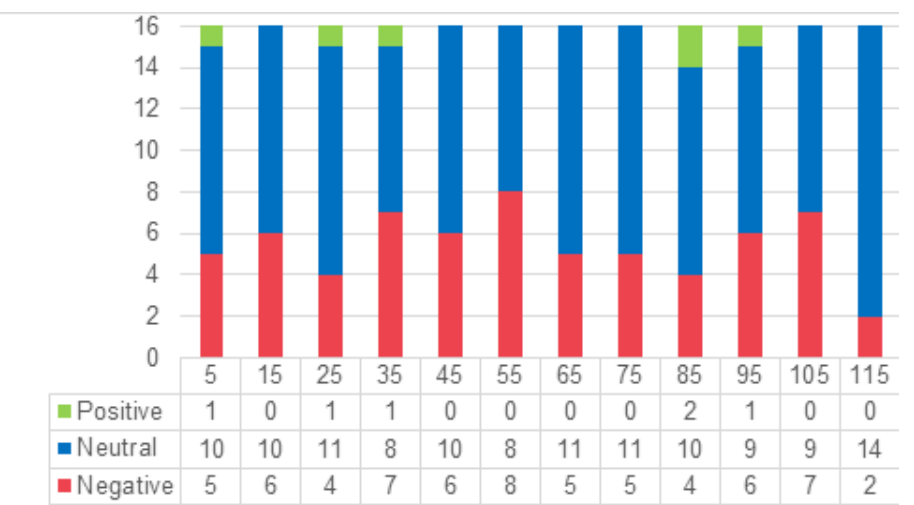

5: Comparison of biometric and brain imaging technology at detection of consumer valence (average) Source: authors' own production 


\section{CONCLUSION}

New technologies are an important part of the new neuromarketing world but they do not represent the most important part which lies in the solution of a problem which the society or public faces. Even usage of the most sophisticated research methods does not guarantee a solution of a problem unless these technologies are applied correctly and combined in a right way to provide elimination of certain deficiencies which every research method contains. We proved in our short research study that the results of the used technologies to detect the consumer valence differ partially. The results from the monitored face expressions indicates that during the video watching dominated the neutral feelings, while the results of the electrical brain activity measurements indicates prevailing negative emotions at subjects during the stimulus watching. The high rate of neutrality in the case of the Facereader software can be caused by the fact that the activity of the somatic nervous system is influential to a certain level (respondent can control his face expression) and as well by the fact that scanning of the face expressions is without contact (no electrode is applied to mimics muscles). We conclude from this that the usage of the technology to monitor the electrical brain activity (EEG) is more precise method of recognizing the consumer valence. However, there were certain anomalies while using this method (positive feelings in cases of strong emotional appeals to fear, sadness and disgust). To gain exact results we recommend the brain imaging technologies combined with the biometric methods which monitor the somatic and autonomous nervous system activity. Regarding various advantages and disadvantages of the technologies used in the neuromarketing research, we can conclude that the combination of at least some of them can produce valuable results for the marketing management depending on the character of the research problem.

\section{Acknowledgements}

The paper is part of the research project KEGA 038SPU-4/2016 "Using of new technologies and interdisciplinary associations in consumer studies" conducted at the Department of Marketing and Trade at the Slovak University of Agriculture in Nitra.

\section{REFERENCES}

AMERICAN ELECTROENCEPHALOGRAPHIC SOCIETY (AES). 1994. Guideline thirteen: guidelines for standard electrode position nomenclature. Journal Clinical Neurophysiology, 11(1): 111-113.

BERČÍK, J., PALUCHOVÁ, J., KLEINOVÁ, K., HORSKÁ, E. and NAGYOVÁ, L. 2014. Stimulus, Space and Hidden Customers Reaction's: Applying Possibilities of Neuromarketing Research. In Proceedings of International Scientific Days: Improving performance of agriculture and the economy: challenges for management and policy. Nitra: Slovak University of Agriculture.

DAVIDSON, R. J. 2004. What does the prefrontal cortex do in affect: Perspectives on frontal asymmetry research. Biological Psychology, 67(1-2): 219-33.

DOOLEY, R. 2012. Brainfluence: 100 ways to persuade and convince consumers with neuromarketing. Canada: John Wiley and Sons.

EKMAN, P. and FRIESEN, W. V. 1978. Facial Action Coding System: A Technique for the Measurement of Facial Movement. Palo Alto: Consulting Psychological Press.

EMOTIS SYSTEMS. 2014. Researchers. [Online]. Available at:http://www.emotiv.com/researchers/ [Accessed: 2014, September 20].

GENCO, S., POHLMANN, A. and STEIDL, P. 2013. Neuromarketing for Dummies. Canada: John Wiley and Sons. HU, S. et.al. 1999. Facial EMG as an indicator of palatability in humans. Physiology $\odot$ Behavior, 68(1-2): 31-35.

KOELSTRA, S. and PATRAS, I. 2013. Fusion of facial expressions and EEG for implicit affective tagging. Image and Vision Computing, 31(2): 164-174.

KOZEL, R., MYNÁŘOVÁ, L. and SVOBODOVÁ, H. 2011. Modern methods and techniques of marketing research [in Czech: Moderni metody a techniky marketingového výzkumu]. Praha: Grada Publishing.

LIBET, B. 2004. Mind time: The temporal factor in consciousness. (Perspectives in cognitive neuroscience). Harvard University Press.

LIN, Y. P. et al. 2008. Support vector machine for EEG signal classification during listening to emotional music. In: Multimedia Signal Processing, IEEE 10 th Workshop, 8-10 Oct. 2008, Cairns, Qld, Australia, pp. 127-130.

MAURI, M. et al. 2014. The effects of social communication: a research study on neuroscientific techniques application. In: Proceedings of the $9^{\text {th }}$ International Conference on Methods and Techniques in Behavioral Research: Measuring Behavior 2014. August 27-29, 2014, Wageningen, pp. 22-27.

NAGEL, C. 2014. Sample Size in Neuromarketing. Neuromarketing Theory G Practice, 9: 6-9.

NOLDUS INFORMATION TECHNOLOGY. 2014. Noldus. [Online]. Available at: http://www.noldus.com/ human-behavior-research/products/facereader [Accessed: 2014, September 12]. 
NOLDUS INFORMATION TECHNOLOGY. 2018. Behavioral research blog. How to use facereader in the lab. Noldus. [Online]. Available at: https://www.noldus.com/blog/how-use-facereader-lab [Accessed: 2018, June 12].

NUWER, M. R. et. al. 1998. IFCN standards for digital recording of clinical EEG. Electroencephalography and Clinical Neurophysiology, 106(3): 259-61.

OHME, R., REYKOWSKA, D., WIENER, D., and CHOROMANSKA, A. 2009. Analysis of neurophysiological reactions to advertising stimuli by means of EEG and Galvanic skin response measures. Journal of Neuroscience, Psychology, and Economics, 2(1): 21-31.

OHME, R., MATUKIN, M. and PACULA - LESNIAK, B. 2011. Biometric measures for interactive advertising research. Journal of Interactive Advertising, 11(2): 60-72.

ÖNAL - HARTMANN, C., OCKLENBURG, P. P. S. and GÜNTÜRKÜN, O. 2012. The motor side of emotions: investigating the relationship between hemispheres, motor reactions and emotional stimuli. Psychological Reseach, 76: 311-316.

PETRANTONAKIS, P. C. and HADJILEONTIADIS, L. J. 2011. A novel emotion elicitation index using frontal brain asymmetry for enhanced EEG-based emotion recognition. IEEE Transactions on Information Technology in Biomedicine, 15(5): 737-46.

PRADEEP, A. 2010. The Buying Brain: Secrets for Selling to the Subconscious Mind. John Wiley \& Sons, Inc.

PURCELL. D. G., STEWART, A. L. and SKOV, R. B. 1996. It takes a confounded face to pop out of a crowd. Perception, 25(9): 1091-108.

RAMIREZ, R. and VAMVAKOUSIS, Z. 2012. Detecting Emotion from EEG Signals Using the Emotive Epoc Device. In: International Conference on Brain Informatics. Vol. 7670. Berlin, Heidelberg: Springer.

RAMPSOY, T. Z. 2014. Introduction to Neuromarketing F Consumer Neurosciense. Rorvig: Neurons Inc Aps.

ROEBUCK, K. 2011. Neuromarketing: High - impact Strategies - What You Need to Know. Lane Cove West: Emereo. SOLEYMANI, M. et. al. 2015. Analysis of EEG Signals and Facial Expressions for Continuous Emotion Detection. IEEE Transactions on Affective Computing, 7(1): 17-28.

TERAZ.SK. 2017. Young drivers and alcohol are the most dangerous factors in road traffic. [in Slovak: Najrizikovejším faktorom v cestnej premávke sú mladí vodiči a alkohol]. Teraz.sk. Available at: http://www. teraz.sk/slovensko/najrizikovejsim-faktorom-v-cestnej-prema/280314-clanok.html [Accessed: 2017, September 13].

VECCHIATO, G., KONG, W., MAGLIONE, A. G. and WEI, D. 2012. Understanding the impact of TV commercials:electrical neuroimaging. IEEE Pulse Magazine, 3(3): 42-7.

WANG, Y.J. and MINOR, M. S. 2008. Validity, reliability, and applicability of psychophysiological techniques in marketing research. Psychology and Marketing, 25(2): 197-232.

ZURAWICKI, L. 2010. Neuromarketing: Exploring the Brain of the Consumer. Heidelberg: Springer.

Katarína Neomániová: katarinakleinova@gmail.com

Jakub Berčík: bercik.jakubxx@gmail.com

Elena Horská: elena.horska@gmail.com 